\title{
Combination of Persistent Scatterer Interferometry and Single-Baseline Polarimetric Coherence Optimisation to Estimate Deformation Rates with Application to Tehran Basin
}

\author{
Zahra Sadeghi $^{1,2}$ - Mohammad Javad Valadan Zoej ${ }^{1} \cdot$ Jan-Peter Muller $^{2}$
}

Received: 1 July 2017 / Accepted: 6 July 2017 / Published online: 27 November 2017

(C) The Author(s) 2017. This article is an open access publication

\begin{abstract}
This study reports on the monitoring of land subsidence in a rural area located in the southwest of the Tehran basin, Iran, by combining a persistent scatterer interferometry (PSI) method with a single-baseline polarimetric coherence optimisation. Owing to vegetation coverage in this rural area, coherence level experiences a decline and the performance and coverage of conventional interferometry to estimate deformation rate reduces concomitantly. Since the launch of satellites with polarimetric information, the polarimetric InSAR (PolInSAR) technique, which is vector interferometry with different polarimetric channels, has been introduced to optimise the coherence level. One of the most common criteria to select PS pixels is coherence and maximising the coherence can lead to an increased number of selected PS pixels and enhanced PSI performance. The single-baseline polarimetric coherence optimisation method assumes equal polarisation states at the end of each baseline. In order to apply this technique in our study, two different multi-look windows for coherence calculation and also two TerraSAR-X data sets with different numbers of images are used to assess their effect on the polarimetric PSI. Combi-
\end{abstract}

The original version of this article was revised due to a retrospective Open Access order.

Zahra Sadeghi

z.sadeghi@ucl.ac.uk

Mohammad Javad Valadan Zoej

valadanzouj@kntu.ac.ir

Jan-Peter Muller

j.muller@ucl.ac.uk

1 Remote Sensing and Photogrammetry Group, Faculty of Geomatics and Geodesy, K.N.Toosi University of Technology, Tehran, Iran

2 Imaging Group, Mullard Space and Science Laboratory, University College London, Holmbury St Mary, UK nation of the single-baseline coherence optimisation method with PSI shows significant improvements (more than 50\%) in terms of the number of selected PS pixels in the case study even using a data set with a small number of images. A $15 \times$ 15 multi-look window selects a greater number of PS pixels compared to a $9 \times 9$ multi-look window, although this entails reducing spatial resolution. The most effective PSI approach in terms of the density of the selected PS turned out to be polarimetric PSI using a data set with a large number of images and a selection of a $15 \times 15$ multi-look window. Validation of the PSI methods using a large number of images with $9 \times 9$ and $15 \times 15$ multi-look windows via levelling measurements confirms the accuracy and reliability of the results obtained.

Keywords PSI · Single-baseline · PolInSAR · Coherence

Zusammenfassung Bestimmung von Bodensenkungsraten mittels Persistent-Scatterer-Interferometrie gestützt durch interferogrammweise Optimierung der polarimetrischen Kohärenz mit Anwendung im Becken von Teheran. Dieser Beitrag beschäftigt sich mit der Überwachung der Bodenabsenkung in einem ländlichen Gebiet im Südwesten des Beckens von Teheran (Iran) mittels Persistent-ScattererInterferometrie (PSI) gestützt durch interferogrammweise Optimierung der polarimetrischen Kohärenz. Auf Grund der Bedeckung des Gebietes mit Vegetation verringert sich der Grad der Kohärenz, wodurch sich die Leistungsfähigkeit von herkömmlichen Verfahren der Interferomtrie zur Bestimmung der Deformationsgeschwindigkeit sowie die Abdeckung durch Persistent Scatterer (PS) verringert. Seit dem Start von Satelliten, die auch polarimetrische Information liefern, kann auch polarimetrische Radarinterferometrie (PolInSAR), also Interferometrie mit verschiedenen Kanälen in verschiedenen Polarisationsrichtungen, dazu 
genutzt werden, um die Kohärenz zu optimieren. Eines der am häufigsten genutzten Kriterien zur Auswahl von PS Pixeln ist die Kohärenz, und die Maximierung der Kohärenz kann zu einer erhöhten Anzahl an ausgewählten PS Pixeln und somit zu besseren PSI-Ergebnissen führen. Die interferogrammweise Optimierung der Kohärenz geht von gleichartigen Polarisationszuständen an beiden Enden jeder dabei berücksichtigten Basislinie aus. In dieser Arbeit werden hierzu zwei verschiedene Fenstergrößen für die Berechnung der Kohärenz durch Mittelung (multi-look) genutzt und auf zwei TerraSAR-X Datensätze mit unterschiedlicher Anzahl an Bildern angewandt, um deren Einfluss auf das Ergebnis zu untersuchen. Es zeigt sich, dass die interferogrammweise Optimierung der Kohärenz sogar dann zu einer Erhöhung der Anzahl der ausgewählten PS Pixel von mehr als 50\% führt, wenn nur wenige Bilder dazu genutzt werden. Die Mittelung über ein größeres Fenster ( 15 x 15$)$ führt zu einer größeren Anzahl als eine Mittelung über ein kleineres Fenster (9 x 9), wenn auch um den Preis einer reduzierten räumlichen Auflösung. Die besten Ergebnisse in Hinblick auf die Dichte der ausgewählten PS wurden mit einem Fenster der Größe 15 x 15 Pixel und einer großen Zahl an Bildern erreicht. Die Genauigkeit und Zuverlässigkeit der Ergebnisse für den Datensatz mit der größeren Anzahl an Bildern wird durch eine Validierung mittels einer durch Nivellement bestimmten Referenz bestätigt.

\section{Introduction}

Differential interferometric synthetic aperture radar (DInSAR) provides precise measurements of surface deformation caused by land subsidence. Conventional DInSAR, however, fails due to strong decorrelation in areas covered primarily by vegetation. Persistent scatterer InSAR (PSI) is an extension to the conventional DInSAR techniques to address the problem of decorrelation. Therefore, PSI has been improved during the last few years in order to identify pixels with coherent scattering behaviour over a sequence of interferograms. In PSI, prior to interferometric processing, a persistent scatterer (PS) pixel selection is applied to all pixels utilising certain criteria. Increasing the number and phase quality of the selected PS pixels can improve performance, especially in vegetated areas, which suffer usually from decorrelation.

A PSI algorithm was outlined first by Ferretti et al. (2000, 2001) with further algorithms quickly following (Colesanti et al. 2003; Lyons et al. 2003). In these algorithms, an initial set of PS pixels are identified by analysis of an amplitude dispersion index. Thus, these algorithms work best where there are a large number of man-made structures. Later, small baseline differential SAR interferometry approaches have selected coherent pixels through spatial coherence estimation and then coherence became one of the main criteria for
PS pixel selection (Berardino et al. 2002; Lanari et al. 2004). Coherence is defined as the absolute value of the normalised complex cross correlation between signals from two images. In fact, it is a measure of the phase noise of the interferogram (Cloude and Papathanassious 1998). The achievable accuracy of the estimation of the interferometric phase is reduced by any loss in coherence (Cloude and Papathanassious 1998). PS pixel identification based on the value of coherence assumes spatial homogeneity of the scattering process and evaluates the accuracy of the interferometric phase through a coherence estimator applied to each interferometric pair (Iglesias et al. 2014). The higher values of coherence lead to better density of identified PS pixels. An alternative PSI method, StaMPS, was presented by Hooper et al. (2007) to identify a large number of PS pixels over all terrain types including non-urban areas that lack man-made structures. This approach uses the spatial correlation of phase for identification of PS pixels. Moreover, three different enhanced PSI algorithms were put forward to improve performance of StaMPS to estimate high-rate deformation over a rural area (Sadeghi et al. 2012; Dehghani et al. 2013; Sadeghi et al. 2013). A new approach, SqueeSAR, was introduced to jointly process PS and distributed scatterers (DS), taking into account their different statistical behaviour. PS and DS can be jointly processed without the need for significant changes to the traditional PSI processing chain (Ferretti et al. 2011).

Interferometric coherence level can be improved using polarimetric information. The concept of PolInSAR (Polarimetric InSAR) was first introduced in Cloude and Papathanassious (1998). One of the key ideas of PolInSAR is that it is possible to obtain interferograms from all possible linear combinations of polarisation states. Cloude and Papathanassious (1998) introduced a general formulation for coherent conventional interferometry using polarimetry, set up a coherence optimisation problem using different polarimetric channels and solved it by maximising the complex Lagrangian which is defined in Cloude and Papathanassious (1998). This method is recognised as the most general one since it allows different polarisation states at the ends of the interferometric baseline. Further work on coherence optimisation methods for DInSAR applications has been proposed (Colin et al. 2006; Neumann et al. 2008). An improvement of the coherence level using polarimetric information helps to find the most coherent and dominant scatterers. Therefore, combination of the coherence optimisation with PSI can lead to the identification of a larger number of PS pixels, and this technique would be beneficial in areas which are covered by vegetation (Navarro-Sanchez et al. 2010; Sadeghi et al. 2017).

This research is focused on monitoring the land subsidence over vegetated areas by integrating a polarimetric coherence optimisation method into the PSI technique. The coherence optimisation method used in this study is proposed 
in Colin et al. (2006) to perform optimisation of singlemechanism coherence which is the coherence assuming the same complex unitary vector for both antennae. As two antennae and the incidence angles are very close in both SAR images producing an interferogram, the single-mechanism coherence adopts equal mechanisms for these antennae (Colin et al. 2005). Furthermore, this technique maximises coherence for each interferogram individually which has been called single-baseline coherence optimisation. Therefore, the optimisation process for every baseline is applied separately. Neumann et al. (2008) introduced multi-baseline coherence optimisation which generally leads to lower coherence magnitudes compared with single-baseline, but the corresponding scattering mechanisms and their interferometric phases are estimated on the basis of all available information and thus, more accurately (Neumann et al. 2008). NavarroSanchez et al. (2010) outlined another multi-baseline coherence optimisation approach which parameterises the scattering mechanisms and finds the optimum multi-baseline coherence via looking in defined search spaces. Moreover, an alternative way to optimise the coherence was proposed to decrease the computation time (Wu et al. 2015). Sadeghi et al. (2017) presented a new multi-baseline coherence optimisation method, the so-called modified coherence set-based polarimetry optimisation (MCPO), which extends Colin's method (which is a single-baseline coherence optimisation) to the multi-baseline case. This method differs slightly from Neumann's method in the optimisation function and initialisation, and works better in increasing the PS density and signal-to-noise ratio (loc.cit.).

Sadeghi et al. (2017) combined MCPO with PSI to apply to a case study using TerraSAR-X images from the Tehran basin. The previous research resulted in increasing the number of identified PS pixels as well as decreasing the phase noise level. As the single-baseline coherence optimisation method leads to higher coherence values compared to multibaseline ones, it is expected to be able to identify a larger number of PS pixels. Therefore, in this study our main goal is to use the single-baseline polarimetric coherence optimisation in the PSI method to test its performance by selecting PS pixels that can be used for estimating deformation. The single-baseline coherence optimisation might entail different dominant scattering mechanisms depending on the chosen baseline and consequently error in the results produced. Therefore, a phase noise analysis is applied to assess the quality of the optimum phase obtained, and then its performance is compared with the implemented MCPO in the current research. Moreover, the single-baseline coherence optimisation method is assessed to improve coherence level with different multi-look window sizes for coherence calculation. Our experiments are carried out on the basis of a set of dual-polarisation TerraSAR-X images of the southwest of the Tehran basin. In order to analyse the performance of polarimetric PSI in cases with insufficient numbers of SAR images, which is a common case in the most of the basins in Iran, a small subset of available images as well as the whole data set are used and their results are compared.

This paper is organised as follows. Section 2 defines a general framework for polarimetric interferometry and a single-baseline coherence optimisation method. In Sect. 3, the selected data sets are introduced. Velocity maps of standard and polarimetric PSI, quantitative comparisons of a number of selected PS pixels between HH, VV and optimum channels for using different multi-look windows and also different data sets, phase quality evaluation and validation of the results are presented in Sect. 4. Finally, the main conclusions are discussed in Sect. 5.

\section{Problem Formulation}

The main goal of this research is applying a combination of the polarimetric single-baseline coherence optimisation method with PSI to estimate a deformation map in a rural area using dual-polarisation TerraSAR-X images. Polarimetric PSI methods generally entail high coherence level, and consequently a larger number of PS pixels can be achieved. In Sect. 2.1, the general concept of polarimetric InSAR is reviewed and in Sect. 2.2 the principles of polarimetric coherence optimisation using the single-baseline method is presented. Finally in the last section, the concept of the PSI technique is outlined.

\subsection{Concept of PolInSAR}

In polarimetric SAR interferometry, a scattering vector, $\mathrm{k}$, is obtained via vectorisation of its scattering matrix, S. Therefore, PolInSAR can be called vector interferometry. Its general formulation was already proposed in Cloude and Papathanassious (1998). In the case of dual-polarisation interferometry, considering there is no data from any crosspolarised channel, the Pauli form of the scattering vector for each pixel can be defined as follows:

$\underline{\mathrm{k}}=\frac{1}{\sqrt{2}}\left[\begin{array}{l}\mathrm{HH}+\mathrm{VV} \\ \mathrm{HH}-\mathrm{VV}\end{array}\right]$,

where $\mathrm{HH}$ and VV are related to horizontal and vertical copolarised channels, respectively. It should be mentioned that for the vectorisation of the scattering matrix, different orthogonal basis sets can be used and therefore different forms of the scattering vector can be employed for polarimetric optimisation. In this research, the Pauli form is selected, because the elements of the resulting scattering vector are closely related to the physics of wave scattering and allow a better interpretation of scattering mechanisms. 
In order to generate an interferogram, a scalar complex value for each pixel can be calculated as a linear combination of the elements of $\underline{\mathrm{k}}$ as $\mu=\underline{\omega}^{\mathrm{H}} \underline{\mathrm{k}}$, where ${ }^{H}$ stands for conjugate transpose. $\omega$ is an unitary complex vector and is called projection vector.

PolInSAR techniques try to find the optimum vector $\omega$ for each pixel in the master and slave images in order to deliver the dominant scattering mechanisms. There is a common optimisation strategy that constrains the optimum $\omega$ vector to be the same for master and slave images $\left(\underline{\omega}_{\text {master }}=\underline{\omega}_{\text {slave }}\right)$ and the single-baseline coherence optimisation method, which is reviewed in Sect. 2.2, uses this constraint.

Assuming the same projection vector for both images, the generalised vector expression for the coherence $\gamma$ is given by

$\gamma=\frac{\left.|| \underline{\omega}^{H}\left[T_{12}\right] \underline{\omega}\right\rangle \mid}{\sqrt{\left\langle\underline{\omega}^{H}\left[T_{11}\right] \omega\right\rangle\left\langle\underline{\omega}^{H}\left[T_{22}\right] \omega\right\rangle}}$,

where $\langle\cdots\rangle$ indicates the expectation operator and $\left[T_{11}\right]$, $\left[T_{22}\right]$ and $\left[T_{12}\right]$ are $2 \times 2$ complex matrices given by

$$
\begin{aligned}
& {\left[T_{11}\right]=\left\langle\mathrm{k}_{1} \mathrm{k}_{1}^{H}\right\rangle} \\
& {\left[T_{22}\right]=\left\langle\mathrm{k}_{2} \mathrm{k}_{2}^{H}\right\rangle} \\
& {\left[T_{12}\right]=\left\langle\mathrm{k}_{1} \mathrm{k}_{2}^{H}\right\rangle,}
\end{aligned}
$$

where $\mathrm{k}_{1}$ and $\mathrm{k}_{2}$ are the scattering vectors for the master and slave images, respectively.

\subsection{Single-Baseline Polarimetric Coherence Optimisation Method}

The single-baseline coherence optimisation method optimises the coherence for every interferogram independently and leads to increase in coherence level (Colin et al. 2006). Because two incidence angles in both SAR images making an interferogram are very close, this method assumes equal mechanisms for two antennae. Matrices $T_{11}$ and $T_{22}$ are very similar as they are both coherence matrices of the target seen under very close incidence angles (Colin et al. 2006). The single-mechanism coherence is introduced in Eq. (4) and it is optimised to estimate optimal projection vectors as shown below:

$\tilde{\gamma}=\frac{\left|\left\langle\underline{\omega}^{H}\left[T_{12}\right] \underline{\omega}\right\rangle\right|}{\left|\left\langle\underline{\omega}^{H}[T] \underline{\omega}\right\rangle\right|}$,

where the matrix $\mathrm{T}$ is defined as $T=\left(T_{11}+T_{22}\right) / 2$ (Tabb et al. 2002). A coherence $\Gamma$ set is the set of all complex coherences as
$\Gamma\left(T_{12}, T\right)=\Omega\left(T^{-\frac{1}{2}} T_{12} T^{-\frac{1}{2}}\right)$,

where $\Omega\left(T^{-\frac{1}{2}} T_{12} T^{-\frac{1}{2}}\right)$ is the field of values or numerical range of the matrix $T^{-\frac{1}{2}} T_{12} T^{-\frac{1}{2}}$, and it is defined by

$\Omega(A)=\left\{x^{H} A x:\|x\|=1\right\}$,

where $A=T^{-\frac{1}{2}} T_{12} T^{-\frac{1}{2}}$. Optimisation of single-mechanism coherence is equivalent to calculating the numerical radius of the matrix $T^{-\frac{1}{2}} T_{12} T^{-\frac{1}{2}}$. The numerical radius of a matrix, $r(A)$, can be found as follows:

$r(A)=\max \left\{\left|x^{H} A x\right|:|x|=1\right\}$.

An iterative numerical approach has been developed to find the radius value of matrix $T^{-\frac{1}{2}} T_{12} T^{-\frac{1}{2}}$ and optimise the single-mechanism coherence. This procedure is for each multi-looked pixel summarised as follows:

1. Compute the matrices $T_{11}, T_{22}, T_{12}, T$ and $A=$ $T^{-\frac{1}{2}} T_{12} T^{-\frac{1}{2}}$.

2. Initialise $\theta=\theta_{0}=\arg (A(1,1)), \theta_{0}[0, \pi]$.

3. Calculate the matrices $A_{\theta}=\mathrm{e}^{i \theta} A$ and $H_{\theta}=\frac{A_{\theta}+A_{\theta}^{H}}{2}$.

4. Estimate the maximum eigenvalue and corresponding eigenvector $(x)$ of $H_{\theta}$.

5. Extract a new value for $\theta$ from $\theta=\arg \left(x^{H} A x\right)$.

6. Iterate steps 3-6 until convergence for $\theta$.

7. Find the optimal vector $\omega=T^{-\left(\frac{1}{2}\right)} x$.

8. Calculate the optimum interferogram $\varphi_{\mathrm{opt}}=\underline{\omega}^{H} T_{12} \underline{\omega}$.

As it was mentioned before, coherence is optimised for each interferogram separately in the single-baseline optimisation method, so the above process is applied to each interferogram individually.

\subsection{Concept of Persistent Scatterer InSAR}

Using a large stack of interferometric SAR images, persistent scatterer InSAR has been developed to overcome the decorrelation problem by identifying types of scatterers known as persistent scatterers. These pixels display coherent scattering behaviour over time (Ferretti et al. 2000, 2001). Therefore, the main concept of PSI techniques is selecting PS pixels and applying the interferometric processing over those pixels to finally estimate the deformation rates. Coherence is one of the most common criteria for PS selection step. Pixels which have coherence higher than a predefined threshold can be selected as PS. Then, according to conventional InSAR, the PS phases have to be unwrapped. The velocity map can be 
found for the PS pixels after removing the estimated phase errors.

In the case of polarimetric PSI, first, the polarimetric coherence optimisation is applied and optimum interferograms are found. Then the PS pixels are selected using the optimum coherence obtained and the pixels that have the optimum coherence larger than a predefined threshold are identified as PS.

\section{Data Sets and Case Study}

The Tehran basin is located in the north of Iran between the Alborz Mountains to the north and the Arad and Fashapouye mountains to the south. The southwestern portion of the basin is subject to high rates of land subsidence caused by overwithdrawal of ground water (Sadeghi et al. 2012, 2013). This subsidence was first revealed by geodetic observations from precise levelling surveys carried out across the area between 1995 and 2002 (Sadeghi et al. 2012).

The southwest of the Tehran basin is primarily covered by vegetation, which reduces the interferometric coherence level due to temporal decorrelation. Therefore, in order to optimise the coherence and, thus, to find more PS pixels for PSI, dual-polarised (HH/VV) TerraSAR-X images were acquired. A set of 22 dual-pol Strip-map images from July 21, 2013 to April 22, 2014 were acquired for the case study. Full-polarisation data set can entail better optimisation results, but unfortunately, TerraSAR-X satellite can only capture images with dual-polarisation information.

Owing to the lack of available polarimetric data sets over Iran for reasons unknown, it was decided to use a small subset of available images as well as the whole data set to assess the performance of the polarimetric PSI in a typical case with limited amounts of data available. A subset of 8 TerraSAR$\mathrm{X}$ images from July 21 to October 6, 2013 with an 11-day time interval was selected as well as the whole 22 data set (from July 21, 2013 to April 22, 2014) with satisfactory temporal baselines. Both data sets were then used to apply polarimetric PSI. The vertical and horizontal axes in Fig. 1 show the spatial and temporal baselines of all single-master interferograms for both data sets, respectively. This figure confirms that spatial and temporal baselines of the available data sets are reasonable and not that large to cause decorrelation. Hereafter, the 8 image data set and the 22 image data set are referred to as the "short" and "long" data sets, respectively.

The study area (outlined rectangle in Fig. 2) is mostly covered by agricultural fields and also contains pixels with the highest rate of deformation. It was selected to combine polarimetric coherence optimisation with PSI.

\section{Results and Discussion}

In this section, results of the polarimetric PSI based on coherence optimisation and standard PSI are presented and their performance to select PS pixels and estimate subsidence rates is compared.

Multi-looking, which is averaging of signals in the spatial domain, is required to calculate coherence. The so-called multi-look factor is the size of a window which is selected to apply multi-looking. In order to implement the polarimetric PSI algorithm, a multi-look factor for the multi-looking process and a coherence threshold for PS identification step must be selected. There are relationships between multi-look factor, coherence and coherence estimate precision as shown below.

Each multi-look factor (window) corresponds to an equivalent number of looks (ENL), which is the number of integrated independent samples. It can be calculated using the multi-look factor, pixel spacing and resolution in azimuth and slant-range orientations as follows (Touzi and Lopes 1999; Navarro-Sanchez et al. 2010):

$L=\frac{\text { pix.spacing (range) }}{\text { resolution (range) }} \cdot \frac{\text { pix.spacing (azimuth) }}{\text { resolution (azimuth) }} N_{\text {pix }}$,

where $L$ is the ENL and $N_{\text {pix }}$ is the multi-look factor. Azimuth and slant-range resolutions of the available stripmap TerraSAR-X data set are 6.6 and $1.17 \mathrm{~m}$, respectively, whereas pixel dimensions are 2.4 and $0.91 \mathrm{~m}$, respectively. Therefore, for multi-look factors, $N_{\text {pix }}$ equal to $9 \times 9$ and $15 \times 15$, the corresponding ENL will be approximately 23 and 64, respectively. According to Eq. (9) derived in Touzi and Lopes (1999), with a predefined ENL there is a relationship between coherence and standard deviation (STD) of coherence estimate. STD values show coherence estimate precision and keeping it under a small threshold entails more accurate estimation. After determination of ENL and selection of coherence threshold, the coherence estimate precision is calculated using Eq. (9):

$\mathrm{STD}=\frac{1-D^{2}}{\sqrt{2 L}}$

where $D$ is the actual coherence magnitude. There is also a sample (measured) coherence magnitude which is an estimate of the actual coherence magnitude $\mathrm{D}$, and is introduced by $\gamma$ in this study. The sample coherence is biased towards higher values, with a resulting reduction of contrast, mainly between areas of differing low coherence. The bias decreases with an increasing number of independent samples $L$ (Touzi and Lopes 1999). Therefore, Eq. (9) is not presenting an exact formulation for calculating the relation between STD and the sample coherence, but it can provide a reasonable estimate 
Fig. 1 a Spatial baselines (vertical axis) vs. temporal baselines (horizontal axis) of slave images in the "short" data set with respect to the master (20130903). b Similarly in the "long" data set with respect to the master (20131211). Bperp is the perpendicular baseline

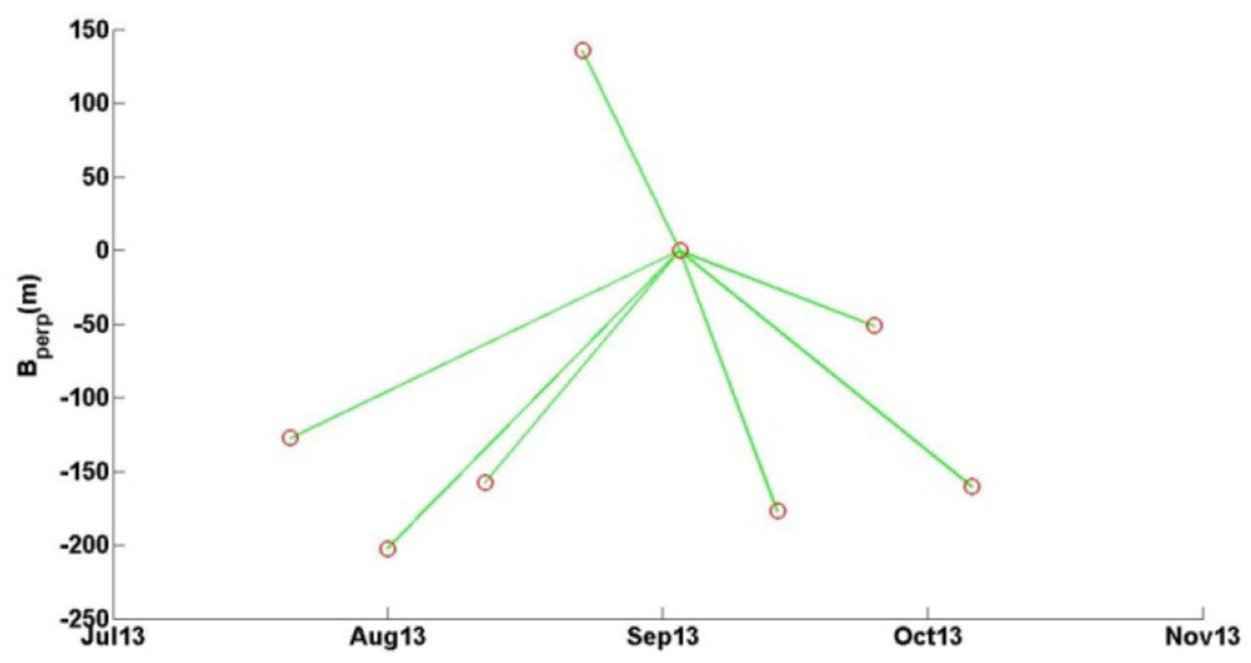

(a)

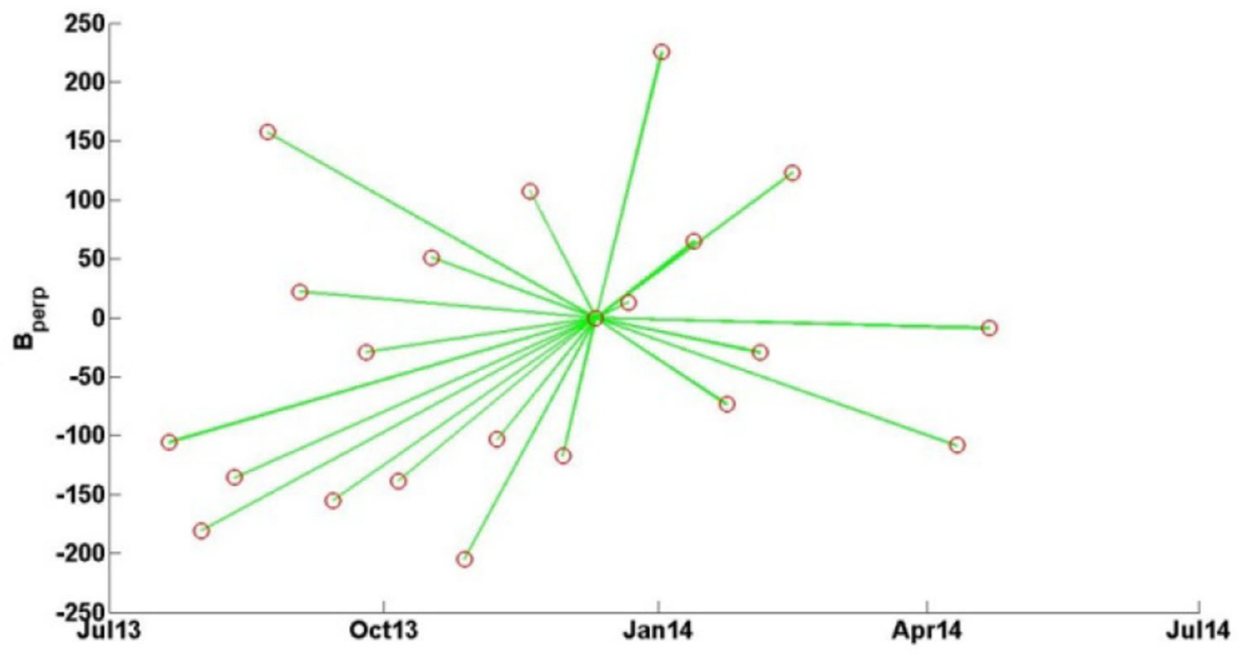

(b) when there is high value coherence or/and a large number of $L$ (e.g. $L \cong 64$ ). There is an analytical expression of the first moment of sample coherence magnitude, as a function of $\mathrm{D}$ and $L$, which was first introduced in Touzi and Lopes (1999).

In this study, the coherence thresholds were selected as 0.6 and 0.4 for $9 \times 9$ and $15 \times 15$ multi-look factors, respectively, and $D$ is assumed to be equal to the sample coherence. Consequently, based on Eq. (9), the corresponding standard deviation for $L \cong 23$ and $L \cong 64$ will be 0.094 and 0.074 , respectively. A smaller threshold of 0.4 was selected for a $15 \times 15$ multi-look factor in comparison with threshold of 0.6 for $9 \times 9$, it is expected that a larger number of identified PS pixels to be achieved for a $15 \times 15$ multi-look factor. In case of selecting similar coherence thresholds for two different multi-look factors, the difference in PS density would be marginal.
Figure 3 shows two diagrams of interferometric processing for standard and polarimetric PSI algorithms. Interferometric pre-processing, e.g. single-master selection and co-registration, used the Doris software (Kampes and Usai 1999). Those pixels which showed coherence values above a certain threshold within at least three interferograms were identified as PS. Interferogram unwrapping and then velocity estimation procedure was applied using the StaMPS software. This software used a 3-D algorithm for unwrapping in spatial and temporal spaces (Hooper et al. 2007). The standard PSI was separately applied to HH and VV channels. The only difference between polarimetric PSI and standard PSI is the polarimetric coherence optimisation step, which was applied in MATLAB, before the PS selection step.

As indicated in Sect. 3, a "short" and a "long" dualpolarised TerraSAR-X data set were chosen to monitor land 
Fig. 2 Coverage area of TerraSAR-X images (black and white rectangle) and selected rural study area in southwest of Tehran basin (red outlined rectangle)

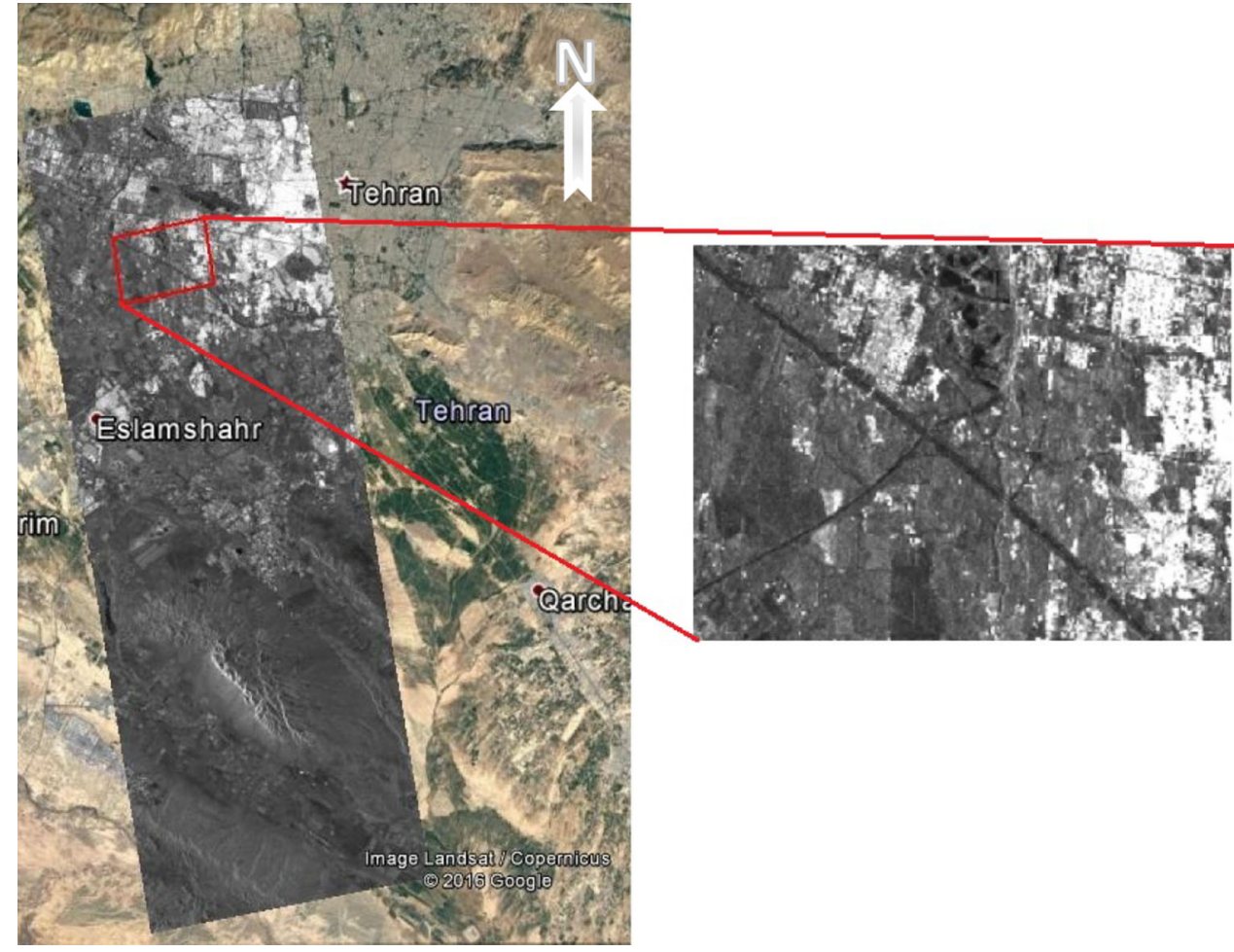

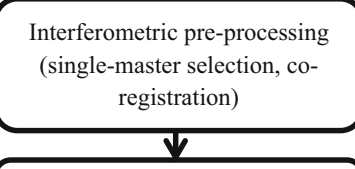

PS selection via coherence value

\section{西}

Velocity map estimation

(a)

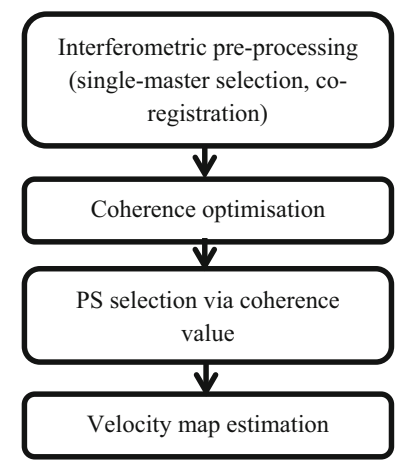

(b)
Fig. 3 Block diagram of a standard PSI processing, $\mathbf{b}$ polarimetric PSI processing

subsidence in a rural case study through polarimetric PSI. The results are presented in the following sections.

\subsection{Results for the "short" Data Set}

The PolInSAR technique obtained interferometric results over the study area shown in the rectangle identified in Fig. 2 via the "short" data set. Tables 1 and 2 show selected PS pixel numbers and percentages acquired from polarimetric PSI and standard PSI with $9 \times 9$ and $15 \times 15$ multi-look windows, respectively. As it can be observed in Tables 1 and 2, polarimetric PSI increases the number and percentage of identified PS pixels significantly with respect to standard PSI. In fact, inspection of Table 1 shows that polarimetric PSI displays
Table 1 Identified PS pixel numbers using the "short" data set and standard and single-baseline polarimetric PSI

\begin{tabular}{lrrl}
\hline Multi-look window & \multicolumn{1}{c}{ HH } & \multicolumn{1}{c}{ VV } & Optimum channel \\
\hline $9 \times 9$ & 14,498 & 12,968 & 26,112 \\
$15 \times 15$ & 5922 & 5061 & 10,728 \\
\hline
\end{tabular}

$\mathrm{HH}, \mathrm{VV}$ and Optimum channel stand for standard PSI using HH channel, standard PSI using VV channel and polarimetric PSI using the single-baseline coherence optimisation, respectively

Table 2 Identified PS pixels percentage (of total) using the "short" data set and standard and single-baseline polarimetric PSI

\begin{tabular}{llll}
\hline Multi-look window & HH $(\%)$ & VV $(\%)$ & Optimum channel (\%) \\
\hline $9 \times 9$ & 22.5 & 20.1 & 40.8 \\
$15 \times 15$ & 25.4 & 21.7 & 46.6 \\
\hline
\end{tabular}

$\mathrm{HH}, \mathrm{VV}$ and Optimum channel stand for standard PSI using HH channel, standard PSI using VV channel and polarimetric PSI using the single-baseline coherence optimisation, respectively

rises of 80.1 and $101.3 \%$ using a $9 \times 9$ multi-look window and rises of 88.1 and $112 \%$ using a $15 \times 15$ multi-look window in terms of PS density in comparison with standard PSI using $\mathrm{HH}$ and VV channels, respectively.

Figures 4 and 5 show LOS (line of sight) velocity maps of standard and optimum PSI for $9 \times 9$ and $15 \times 15$ multilook windows, respectively. According to these figures, it is clear that coherence optimisation via dual-polarimetric information has been successful in increasing PS pixel density. 
Fig. 4 LOS subsidence velocity map of the "short" data set using $9 \times 9$ multi-look window with a coherence threshold of 0.6 for a standard PSI using HH channel, b standard PSI using VV channel, c polarimetric PSI

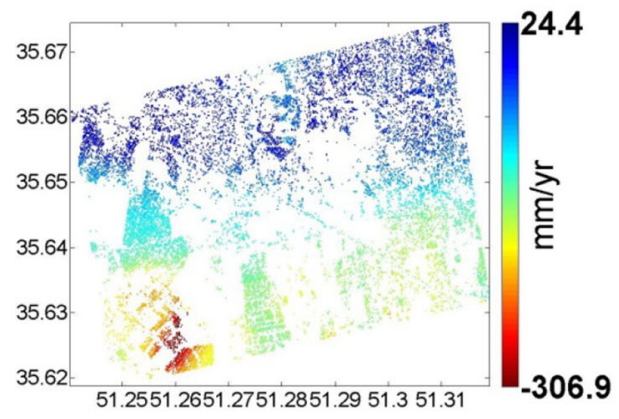

(a)

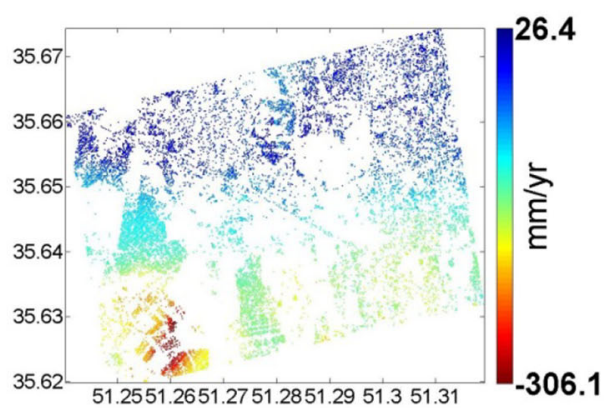

(b)

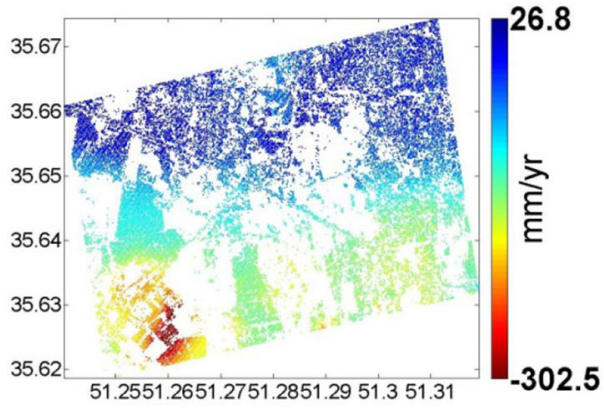

(c)

Fig. 5 LOS subsidence velocity map of the "short" data set using a $15 \times 15$ multi-look window with a coherence threshold of 0.4 for a standard PSI using HH channel, b standard PSI using VV channel, c polarimetric PSI

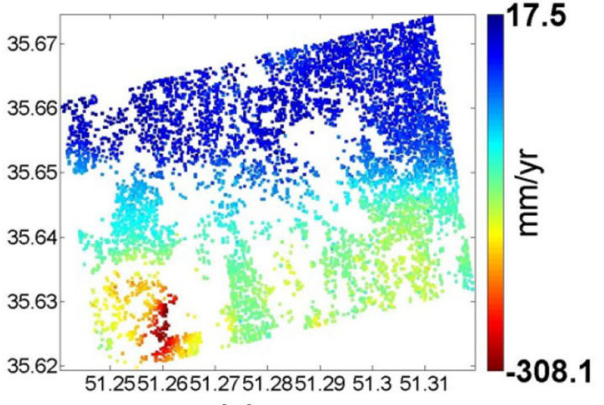

(a)

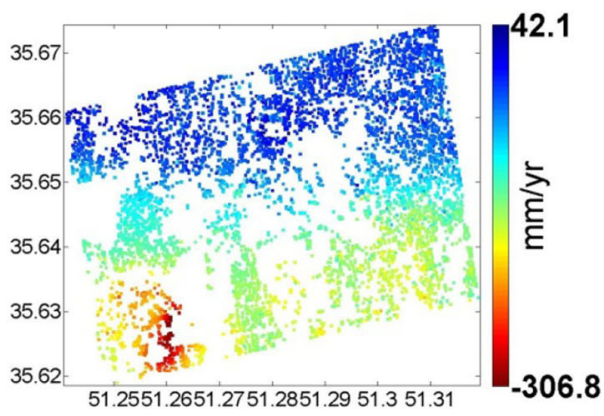

(b)

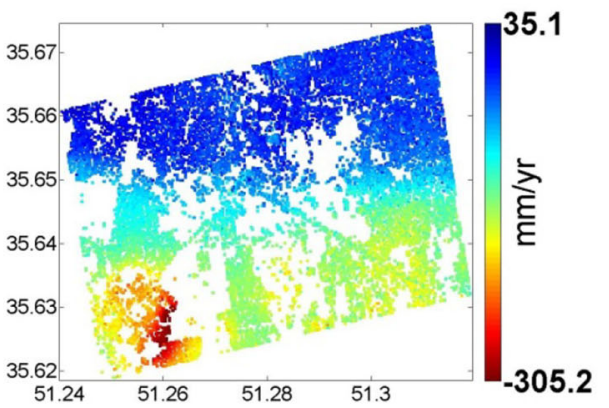

(c)

Moreover, choosing a $15 \times 15$ multi-look window with a coherence threshold of 0.4 led to identification of more PS pixels compared to a $9 \times 9$ multi-look window with a coherence threshold of 0.6.

\subsubsection{Evaluation of Phase Quality}

In this section, a phase noise analysis for the polarimetric PSI method is applied according to Hooper et al. (2007) to evaluate the phase quality. Therefore, the phase noise values are estimated and compared with the standard PSI. In order to apply the phase noise analysis, first, the identified PS pixels are connected to form a network using Delaunay triangulation. Then double difference phase measurements are constructed as the differenced phases in space and time for each arc connecting two PS pixels. For each double difference phase a weighted-average phase is calculated and subtracted from the original double difference phase. Then a low-pass 
Fig. 6 Histogram of std-noise for mutual formed arcs between polarimetric PSI and a standard PSI using HH channel for $9 \times 9$ multi-look window, b standard PSI using VV channel for $9 \times 9$ multi-look window, $\mathbf{c}$ standard PSI using $\mathrm{HH}$ channel for $15 \times$ 15 multi-look window, $\mathbf{d}$ standard PSI using VV channel for $15 \times 15$ multi-look window. Blue and red lines indicate the polarimetric and standard PSI behaviour, respectively

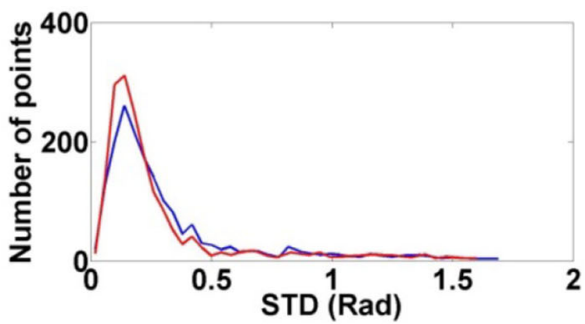

(a)

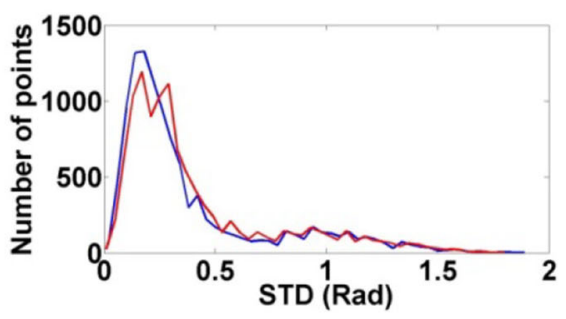

(c)

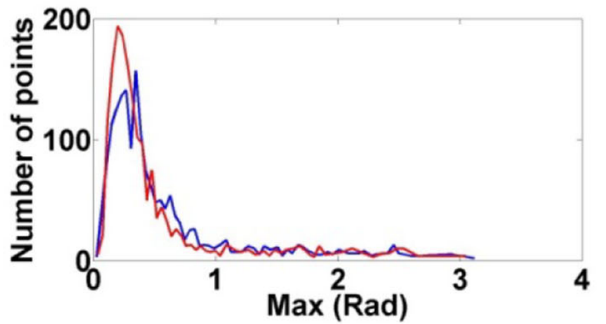

(a)

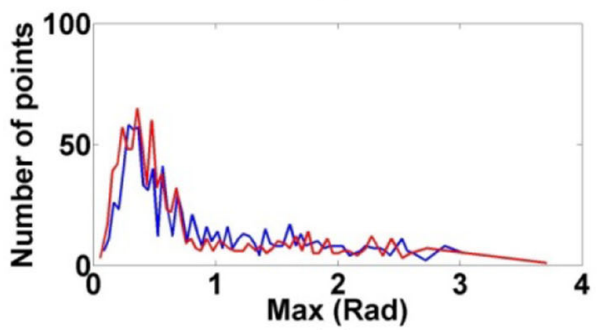

(c)

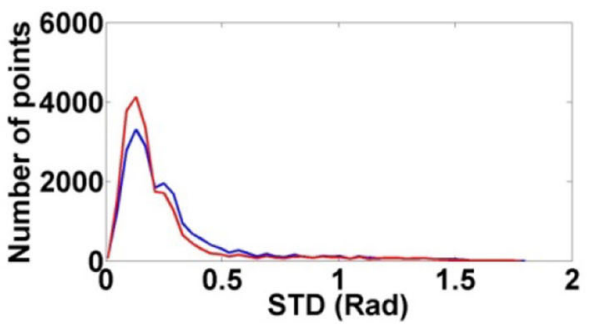

(b)

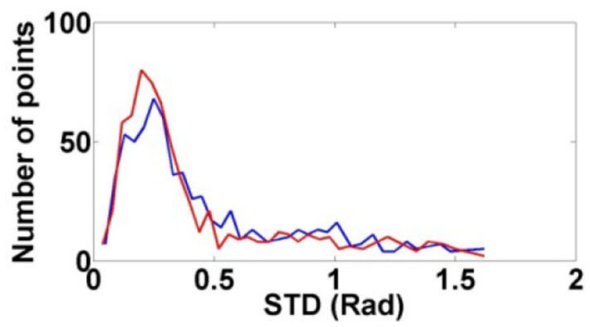

(d)

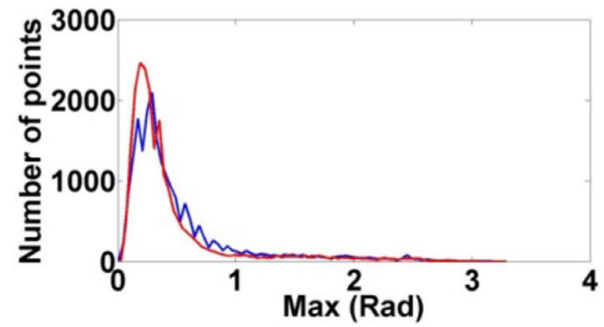

(b)

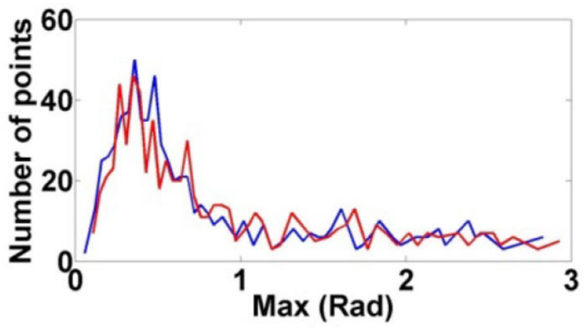

(d) filter is applied over the residual phase and the obtaining phase with the weighted-average phase estimate the smooth phase. Subtracting the smooth phase from the original double difference phase estimates phase noise. For each vector of double difference phase, which contains phase values of an arc in all available interferograms, a vector of noise components is estimated. Subsequently, the maximum magnitude of the vector of phase noise, denoted max-noise, and the standard deviation of vector of phase noise, named std-noise, are obtained for each arc. Then, the estimated max-noise and std-noise for mutual formed arcs between the polarimetric PSI and standard PSI are compared to assess the effect of polarimetric optimisation on the phase noise. Figures 6 and 7 display histograms of the estimated max-noise and std-noise for the optimum channel obtained by the polarimetric PSI in a comparison with standard PSI using HH and VV channels. These figures illustrate that the single-baseline polarimetric PSI increases the number of arcs with max-noise and std-noise higher than 0.5 (rad) with respect to standard PSI. Therefore, a threshold of 0.5 was selected to compare the noise phase level of the PSI approaches.

Tables 3 and 4 show the percentage increase in the number of mutual arcs with std-noise and max-noise higher than (0.5) through the single-baseline polarimetric PSI in comparison with standard PSI (HH and VV channels). This comparison confirms that in spite of increasing coherence level and consequently PS density, this method is not successful in reducing the noise level of arcs selected by standard PSI. 
Table 3 Percentage increase in the number of arcs with std-noise higher than 0.5 (rad) in the optimum channel obtained by the single-baseline polarimetric PSI with respect to standard PSI

\begin{tabular}{lcl}
\hline Multi-look window & HH $(\%)$ & VV $(\%)$ \\
\hline $9 \times 9$ & 3.5 & 3.4 \\
$15 \times 15$ & 10.1 & 6.4
\end{tabular}

$\mathrm{HH}$ and VV stand for standard PSI using $\mathrm{HH}$ and VV channels, respectively. The percentage was calculated using the ratio of increase in number of arcs with std-noise higher than 0.5 (rad) to all arcs

Table 4 Percentage increase in the number of arcs with max-noise higher than 0.5 (rad) in the optimum channel obtained by the singlebaseline polarimetric PSI with respect to standard PSI

\begin{tabular}{lll}
\hline Multi-look window & HH $(\%)$ & VV $(\%)$ \\
\hline $9 \times 9$ & 9.2 & 9.6 \\
$15 \times 15$ & 9.8 & 5.6 \\
\hline
\end{tabular}

$\mathrm{HH}$ and VV stand for standard PSI using $\mathrm{HH}$ and VV channels, respectively. The percentage was calculated using the ratio of increase in number of arcs with max-noise higher than 0.5 (rad) to all arcs

Table 5 Identified PS pixels percentage (of total) using the "short" data set and multi-baseline polarimetric PSI (Sadeghi et al. 2017)

\begin{tabular}{ll}
\hline Multi-look window & Optimum channel $(\%)$ \\
\hline $9 \times 9$ & 31.9 \\
$15 \times 15$ & 36.1 \\
\hline
\end{tabular}

Optimum channel stands for polarimetric PSI using the multi-baseline coherence optimisation

\subsubsection{Comparison with Multi-Baseline Polarimetric PSI}

As was mentioned in Sect. 1, MCPO was presented by Sadeghi et al. (2017) and applied to the same study area using the "short" data set. In addition to increasing the number of PS pixels, this multi-baseline polarimetric coherence optimisation method is successful in reducing the noise level of the mutual arcs. Table 5 displays the percentage of selected PS pixels in the case study using MCPO. A comparison with Table 2 confirms that the single-baseline coherence optimisation method increased number of the identified PS pixels by 8.9 and $10.5 \%$ with respect to MCPO.

Moreover, a similar phase noise analysis was applied to verify the quality of the optimum phase obtained by MCPO. Tables 6 and 7 present percentage decrease in the number of mutual arcs with std-noise and max-noise higher than 0.5 (rad) in the results of MCPO with respect to $\mathrm{HH}$ and VV channels. As can be seen, MCPO works better than the single-baseline polarimetric coherence optimisation in reducing the noise level, as it optimises the multi-baseline coherence simultaneously and finds the most coherent and dominant scatterers.
Table 6 Percentage decline in the number of arcs with std-noise higher than 0.5 (rad) in the optimum channel obtained by the multi-baseline polarimetric PSI with respect to standard PSI

\begin{tabular}{lll}
\hline Multi-look window & HH $(\%)$ & VV $(\%)$ \\
\hline $9 \times 9$ & 2.24 & 1.81 \\
$15 \times 15$ & 4.2 & 5.91
\end{tabular}

$\mathrm{HH}$ and VV stand for standard PSI using HH and VV channels, respectively (Sadeghi et al. 2017). The percentage was calculated using the ratio of decline in number of arcs with std-noise higher than 0.5 (rad) to all arcs

Table 7 Percentage decline in the number of arcs with max-noise higher than $0.5(\mathrm{rad})$ in the optimum channel obtained by the multibaseline polarimetric PSI with respect to standard PSI

\begin{tabular}{lll}
\hline Multi-look window & HH $(\%)$ & VV $(\%)$ \\
\hline $9 \times 9$ & 6.02 & 5.26 \\
$15 \times 15$ & 9.3 & 12.66 \\
\hline
\end{tabular}

$\mathrm{HH}$ and VV stand for standard PSI using HH and VV channels, respectively (Sadeghi et al. 2017). The percentage was calculated using the ratio of decline in number of arcs with max-noise higher than 0.5 (rad) to all arcs

Table 8 Identified PS pixels number using the "long" data set and standard and single-baseline polarimetric PSI

\begin{tabular}{lrrl}
\hline Multi-look window & \multicolumn{1}{c}{ HH } & \multicolumn{1}{c}{ VV } & Optimum channel \\
\hline $9 \times 9$ & 12,185 & 11,542 & 23,367 \\
$15 \times 15$ & 8406 & 7959 & 12,630 \\
\hline
\end{tabular}

$\mathrm{HH}, \mathrm{VV}$ and Optimum channel stand for standard PSI using HH channel, standard PSI using VV channel and polarimetric PSI using the single-baseline coherence optimisation, respectively

Table 9 Identified PS pixels percentage (of total) using the "long" data set and standard and single-baseline polarimetric PSI

\begin{tabular}{llll}
\hline Multi-look window & $\mathrm{HH}(\%)$ & $\mathrm{VV}(\%)$ & Optimum channel (\%) \\
\hline $9 \times 9$ & 17.3 & 16.4 & 33.3 \\
$15 \times 15$ & 33.3 & 31.6 & 50.1 \\
\hline
\end{tabular}

$\mathrm{HH}, \mathrm{VV}$ and Optimum channel stand for standard PSI using HH channel, standard PSI using VV channel and polarimetric PSI using the single-baseline coherence optimisation, respectively

\subsection{Results for the "long" Data Set}

Polarimetric interferometric processing was applied over a study area shown in the rectangle in Fig. 2 using the "long" data set. Tables 8 and 9 display the numbers and percentages of identified PS pixels by polarimetric PSI and standard PSI with $9 \times 9$ and $15 \times 15$ multi-look windows. This shows similar behaviour as the "short" data set. PSI performance has been dramatically improved in terms of the number of selected PS pixels via the single-baseline polarimetric optimisation method. Inspection of Table 8 shows that the density 
Fig. 8 LOS subsidence velocity map of the "long" data set using $9 \times 9$ multi-look window with a coherence threshold of 0.6 for a standard PSI using HH channel, b standard PSI using VV channel, c polarimetric PSI

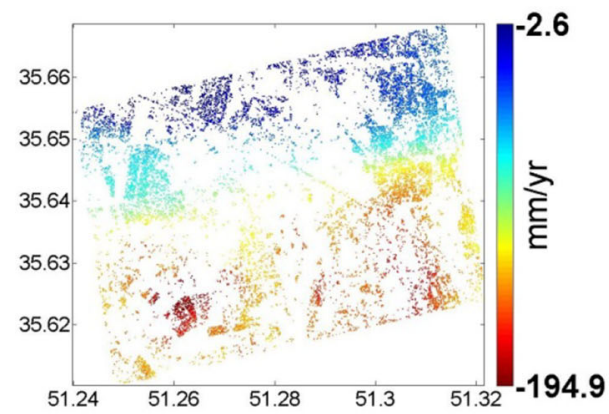

(a)

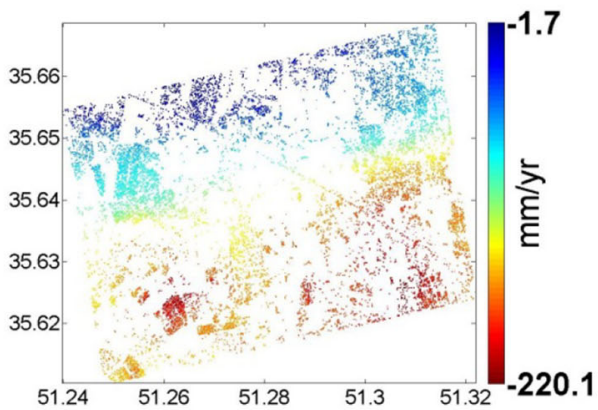

(b)

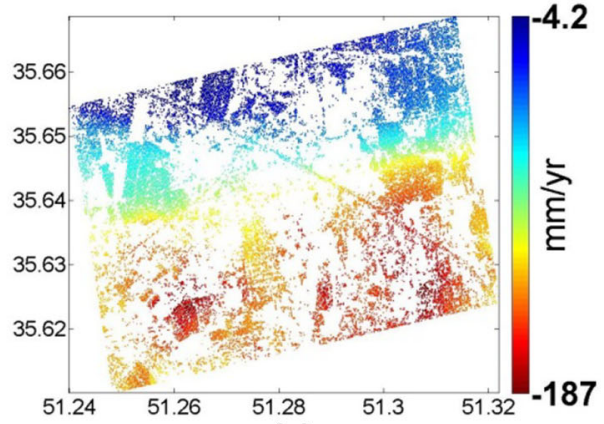

(c)

Fig. 9 LOS subsidence velocity map of the "long" data set using $15 \times 15$ multi-look window with a coherence threshold of 0.4 for a standard PSI using HH channel, b standard PSI using VV channel, c polarimetric PSI

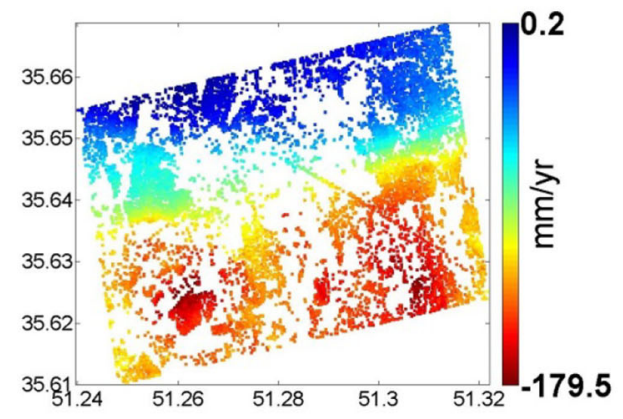

(a)

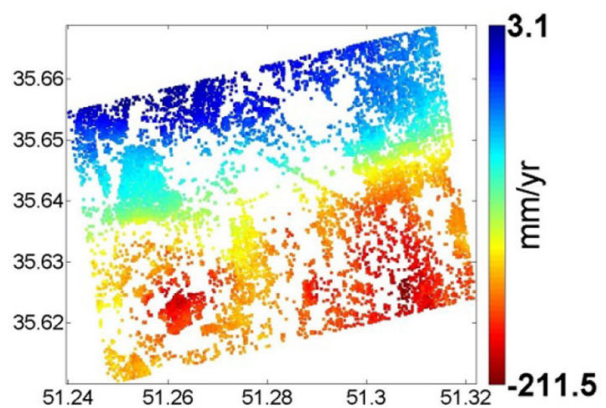

(b)

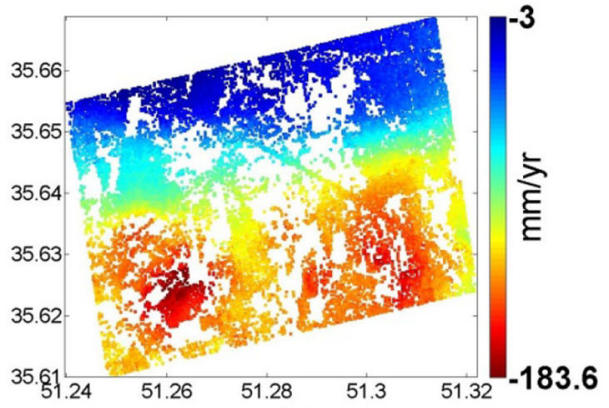

(c)

of the selected PS in the optimum channel obtained by the polarimetric PSI has increased by 91 and $100.2 \%$ using $9 \times 9$ multi-look window and 50.2 and $58.6 \%$ using $15 \times 15$ multilook window with respect to standard PSI using separate $\mathrm{HH}$ and VV channels, respectively.

Velocity maps of standard PS interferometry and optimum PS interferometry using either $9 \times 9$ and $15 \times 15$ multi-look windows are shown in Figs. 8 and 9, respectively. Similar to the outcomes of the "short" data set, the single-baseline polarimetric PSI with $15 \times 15$ multi-look window and coherence threshold of 0.4 is identified as the best enhancement method in terms of the number of selected PS pixels.

As mentioned before, the combination of larger multi-look window with a lower coherence threshold entails a larger number of identified PS pixels. As a result, a $15 \times 15$ multilook window with coherence threshold of 0.4 works better 


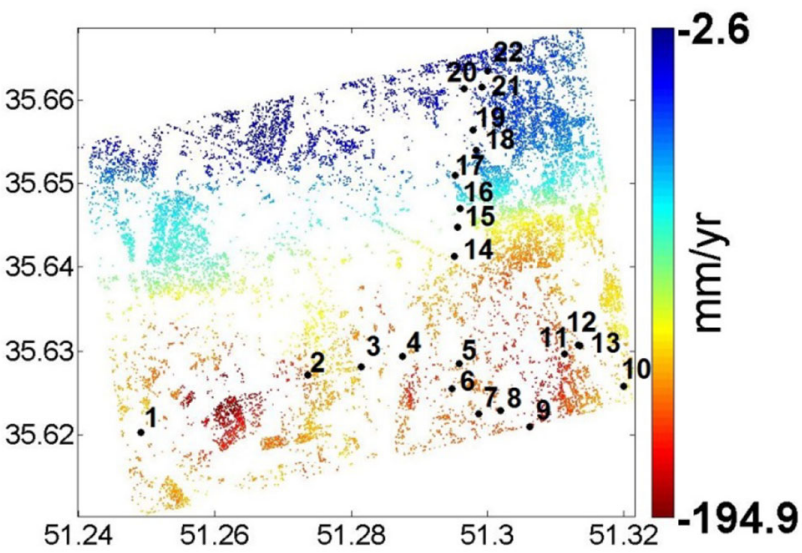

Fig. 10 Spatial location of levelling stations in the case study. The background is the deformation map estimated using standard PSI (using $\mathrm{HH}$ channel) with $9 \times 9$ multi-look factor

than a $9 \times 9$ multi-look window in increasing the selection of PS pixels using both "short" and "long" data sets. However, the selection of a larger multi-look window is a trade-off between coarser spatial resolution and lower coherence threshold.

Despite of the success of the single-baseline polarimetric PSI using the "short" data set with a $15 \times 15$ multi-look window in identifying more PS pixels with respect to a $9 \times 9$ multi-look window, the percentages of selected PS pixels are close (see Table 2). Using the "long" data set with a $15 \times$ 15 multi-look window, this method has been able to select many more PS pixels in comparison with a $9 \times 9$ multi-look window (see Table 9). Therefore, the best PSI method to select more PS pixels in this rural area in the Tehran basin is polarimetric PSI using the "long" data set with a $15 \times 15$ multi-look window.

Since a large number of SAR images usually leads to more reliable results in the PSI technique than a small sample, and also because available levelling measurements in the case study had a mutual observing period with the "long" data

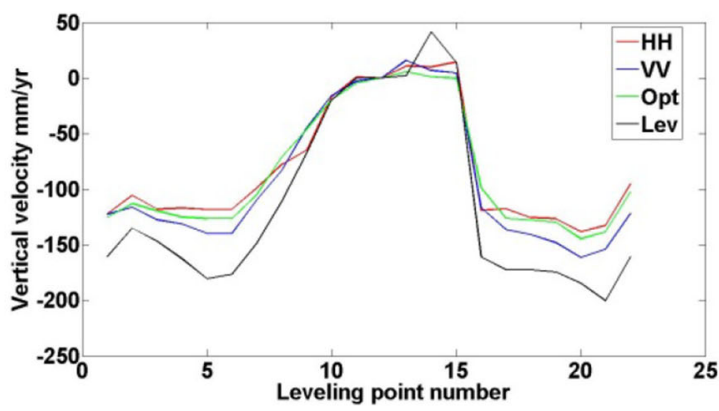

(a)

Fig. 11 Comparison of subsidence vertical velocities inferred from the single-baseline polarimetric PSI and standard PSI using the "long" data set and levelling measurements along 22 levelling stations with $\mathbf{a} 9 \times 9$
Table 10 RMSE (mm/yr) values between vertical velocities of PSI algorithms and levelling measurements with two different multi-look factors

\begin{tabular}{llll}
\hline Multi-look factor & HH & VV & Optimum channel \\
\hline $9 \times 9$ & 26.3 & 19.8 & 26.7 \\
$15 \times 15$ & 29.1 & 21.5 & 31.7 \\
\hline
\end{tabular}

$\mathrm{HH}, \mathrm{VV}$ and Optimum channel stand for standard PSI using HH channel, standard PSI using VV channel and polarimetric PSI using the single-baseline coherence optimisation, respectively

set, the velocities obtained via single-baseline polarimetric PSI using the "long" data set were evaluated quantitatively using levelling observations in this study. Levelling measurements were obtained with third-order accuracy during two epochs on September 23, 2013 and April 23, 2014, which is not contemporaneous with the "long" data set regarding the start date. There are 22 levelling stations in the case study as can be observed in Fig. 10. Figure 11 depicts the comparison between the derived vertical velocities from PSI algorithms with $9 \times 9$ and $15 \times 15$ multi-look windows using all the data set and observed velocities from levelling measurements in $\mathrm{mm} /$ year at the levelling stations. The nearest PS pixel was selected to extract the rate of deformation by PSI for each levelling station. As shown in this figure, the spatial pattern of subsidence obtained from the PSI methods agrees closely with the levelling measurements for most of the levelling stations in both cases. Table 10 shows the RMSE values of comparison with levelling measurements at the levelling stations for the PSI methods, and confirms the accuracy of estimated deformation rates by the standard and polarimetric PSI method. Although the single-baseline polarimetric PSI method improves the number of PS pixels significantly, it is not successful in terms of improving the deformation accuracy, because this method increases the level of phase noise as it was shown in Sect. 4.1. However, the differences between estimated RMSEs by the polarimetric PSI and the standard ones are insignificant. It should be mentioned that

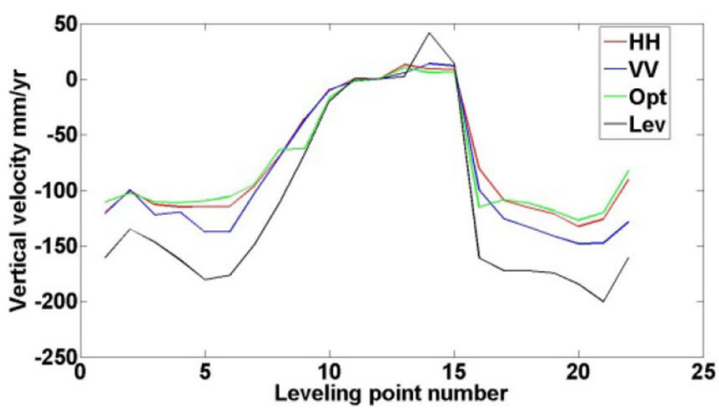

(b)

multi-look window, b $15 \times 15$ multi-look window, the reference point is number 19 in Fig. 9 
single-baseline coherence optimisation can reproduce phase errors due to independent optimisation for every baseline and this error can affect the obtained RMSE by polarimetric PSI. Moreover, the selection of a $9 \times 9$ multi-look window entails more accurate estimation of deformation rather than $15 \times 15$. It should be mentioned that the temporal sampling of levelling measurements was relatively poor and also their unsatisfactory accuracy can be recognised as reasons for estimated different rates.

\section{Conclusions}

In this paper, a combination of a single-baseline polarimetric coherence optimisation with a PSI technique has been applied to a vegetated area which suffers from land subsidence, and its performance has been compared with a combination of a multi-baseline coherence optimisation with PSI. A coherence optimisation process using dual-polarimetric information has been applied before PS pixel selection. Due to the improvement in coherence level, a larger number of PS pixels has been identified.

As multi-looking for coherence estimation is mandatory, $9 \times 9$ and $15 \times 15$ multi-look windows were chosen to assess the effect of this factor on the polarimetric PSI results. Based on the equation extracted from Touzi and Lopes (1999), coherence thresholds were calculated approximately as 0.6 and 0.4 for $9 \times 9$ and $15 \times 15$ multi-look factors, respectively, in order to keep the standard deviation of coherence below 0.094 and 0.074. Moreover, all dual-polarisation TerraSAR$\mathrm{X}$ images as well as the first 8 images considered as a different data set were utilised individually to assess the single-baseline polarimetric PSI approach performance.

The single-baseline polarimetric PSI using the "short" data set (comprising unsatisfactory number of images) improved the number of PS pixels by 101.3 and $112 \%$ with respect to standard PS InSAR (VV channel) via selection of a $9 \times 9$ and a $15 \times 15$ multi-look window, respectively. Furthermore, this polarimetric PSI method using the "long" data set (comprising satisfactory number of images) increased the number of PS pixels by 100.2 and $58.6 \%$ in comparison to single-pol PSI (VV channel) through selection of a $9 \times 9$ and a $15 \times 15$ multi-look window, respectively. Therefore, it is clear that the single-baseline polarimetric PSI method has boosted the density of selected PS pixels seriously.

The polarimetric PSI results have shown that coherence calculation with a $15 \times 15$ multi-look window and 0.4 coherence threshold identified a greater number of PS pixels with respect to $9 \times 9$ and 0.6 using both the "short" and "long" data sets. Although, using larger multi-look window results in lower spatial resolution.

Moreover, this study has displayed that the density of selected PS pixels by polarimetric PSI using the "long" data set is higher than using the "short" data set. Thus, the most enhanced PSI approach in terms of number of selected PS pixels is the single-baseline polarimetric PSI using all data set, $15 \times 15$ multi-look window and 0.4 coherence threshold which was able to select $50.1 \%$ of pixels as PS.

Because the single-baseline polarimetric coherence optimisation method optimises each interferogram separately, it entails identifying different dominant scattering mechanisms depending on the chosen baseline and consequently produces phase noise. Therefore, in this research, a phase noise analysis was applied to evaluate the quality of the resultant optimum phases, and then the outputs were compared with the results of the multi-baseline coherence optimisation method, MCPO. The single-baseline polarimetric PSI increased the noise level of phases with respect to standard PSI, whilst the multi-baseline polarimetric PSI was successful in reducing in phase noise level. It should be mentioned that the single-baseline polarimetric PSI increased the numbers of the selected PS pixels by 8.9 and $10.5 \%$ with respect to the multi-baseline one.

The estimated deformation rate by standard and polarimetric PSI using the "long" data set has been validated through available levelling measurements. This evaluation verified the accuracy and reliability of the obtained results, and it was concluded that the single-baseline coherence optimisation was not successful in increasing the deformation estimation accuracy due to increasing the phase noise. Developing a new PSI method, which can improve the PS density and decrease the phase noise level, is suggested for future work.

Acknowledgements All TerraSAR-X images have been provided by DLR in the framework of the LAN1335 Project.

Open Access This article is distributed under the terms of the Creative Commons Attribution 4.0 International License (http://creativecomm ons.org/licenses/by/4.0/), which permits unrestricted use, distribution, and reproduction in any medium, provided you give appropriate credit to the original author(s) and the source, provide a link to the Creative Commons license, and indicate if changes were made.

\section{References}

Berardino P, Fornaro G, Lanari R, Sansosti E (2002) A new algorithm for surface deformation monitoring based on small baseline differential SAR interferograms. IEEE Trans Geosci Rem Sens 40(11):2375-2383

Cloude SR, Papathanassious P (1998) Polarimetric SAR interferometry. IEEE Trans Geosci Rem Sens 36(5):1551-1565. https://doi.org/ $10.1109 / 36.718859$

Colesanti C, Ferretti A, Novali F, Prati C, Rocca F (2003) Monitoring landslides and tectonic motions with the permanent scatterers technique. Eng Geol 68:3-14. https://doi.org/10.1016/ S0013-7952(02)00195-3

Colin E, Titin-Schnaider C, Tabbara W (2006) An interferometric coherence optimisation method in radar polarimetry for high-resolution 
imagery. IEEE Trans Geosci Rem Sens 44(1):167-175. https://doi. org/10.1109/TGRS.2005.859357

Colin E, Titin-Schnaider C, Tabbara W (2003) Investigation on different IFPOL coherence optimisation methods. In: Presented at the POLINSAR. ESRIN-ESA, Frascati, Italy

Dehghani M, Valadan Zoej MJ, Hooper A, Hanssen R, Entezam I, Saatchi S (2013) Hybrid conventional and persistent scatterer SAR interferometry for land subsidence monitoring in the Tehran Basin, Iran. ISPRS J Photogramm Rem Sens 79:157-170

Ferretti A, Prati C, Rocca F (2000) Permanent scatterers in differential SAR interferometry. IEEE Trans Geosci Rem Sens 38(5):22022212

Ferretti A, Prati C, Rocca F (2001) Permanent scatterers in SAR interferometry. IEEE Trans Geosci Rem Sens 39(1):8-20. https://doi. org/10.1109/36.898661

Ferretti A, Fumagalli A, Novali F, Prati C, Rocca F, Rucci A (2011) A new algorithm for processing interferometric data-stacks: SqueeSAR. IEEE Trans Geosci Rem Sens 49(9):3460-3470

Hooper A, Segall P, Zebker H (2007) Persistent scatterer interferometric synthetic aperture radar for crustal deformation analysis with application to Vacan Alcedo. J Geophys Res 112. https://doi.org/ 10.1029/2006JB004763B07407

Iglesias R, Monells D, Fabregas X, Mallorqui JJ, Aguasca A, Lopezmartinez C (2014) Phase quality optimisation polarimetry differential SAR interferometry. IEEE Trans Geosci Rem Sens 52(5):2875-2888. https://doi.org/10.1109/TGRS.2013.2267095

KAMPES B. \& USAI S (1999) Doris: the delft object-oriented radar interferometric software. In: Proceedings ITC 2nd ORS symposium

Lanari R, Mora O, Manunta M, Mallorquì JJ, Berardino P, Sansosti E (2004) A small baseline approach for investigating deformations on full resolution differential SAR interferograms. IEEE Trans Geosci Rem Sens 42(7):1377-1386

Lyons S, Sandwell D (2003) Fault creep along the southern San Andreas from interferometric synthetic aperture radar. J Geophys Res 108(B1):2047-2070
Navarro-Sanchez VD, Lopez-Sanchez JM, Vicente-Guijalba F (2010) A contribution of polarimetry to satellite differential SAR interferometry: increasing the number of pixel candidates. IEEE J Select Top Appl Earth Obs Rem Sens 7(2):276-280

Neumann M, Ferro-Famil L, Reigber A (2008) Multibaseline polarimetric SAR Interferometry coherence optimisation. IEEE Geosci Rem Sens Lett 5(1):93-97. https://doi.org/10.1109/TGRS.2005. 859357

Sadeghi Z, Valadan ZOEJMJ, Dehghani M (2013) An improved persistent scatterer interferometry for subsidence monitoring in the Tehran basin. IEEE J Select Top Appl Earth Obs Rem Sens 6(3):1571-1577. https://doi.org/10.1109/JSTARS.2013.2259221

Sadeghi Z, Valadan ZOEJMJ, DEHGHANI M, (2012) Enhanced algorithm based on persistent scatterer interferometry for the estimation of high-rate land subsidence. J Appl Rem Sens 6(1). https:// doi.org/10.1117/1.JRS.6.063573

Sadeghi Z, Valadan ZOEJMJ, Muller JP (2017) Monitoring land subsidence in a rural area using a combination of ADInSAR and polarimetric coherence optimisation. IEEE J Select Top Appl Earth Obs Rem Sens 99:1-9. https://doi.org/10.1109/JSTARS. 2017.2689823

TABB M, ORREY J, FLYNN,T, CARANDE R (2002) Phase diversity: a decomposition for vegetation parameter estimation using polarimetric SAR interferometry. In: Presented at EUSAR, cologne, Germany

Touzi R, Lopes A (1996) Statistics of the Stokes parameters and of the complex coherence parameters in one-look and multi-look speckle field. IEEE Trans Geosci Rem Sens 34(2):519-532

Touzi R, Lopes A, Bruniquel J, Vachon WP (1999) Coherence estimation for SAR imagery. IEEE Trans Geosci Rem Sens 37(1):135148. https://doi.org/10.1109/36.739146

Wu B, Tong L, Chen Y, He L (2015) New methods in multibaseline polarimetric SAR interferometry coherence optimisation. IEEE Geosci Rem Sens Lett 12(10):2016-2020 